\title{
Changes in Auditory Selective Attention and Event-Related Potentials Following Oral Administration of D-amphetamine in Humans
}

Rebecca McKetin, B.S. (Psychol.), Philip B. Ward, Ph.D., Stanley V. Catts, M.D., Richard P. Mattick, Ph.D., and James R. Bell, F.R.A.C.P.

The effect of $d$-amphetamine on selective attention in humans was investigated by measuring event-related potentials (ERPs) during a complex auditory selective attention task (CSAT). The CSAT required subjects to make a button press response to infrequent target tones presented amongst tones that varied in pitch (high vs. low), location (left vs. right ear) and duration (51 ms vs. $102 \mathrm{~ms}$ ). Healthy subjects completed the CSAT under three conditions:

placebo, $10 \mathrm{mg}$ and $20 \mathrm{mg}$ d-amphetamine, at least one week apart. D-amphetamine produced a significant dose response increase in hit-rate and decrease in reaction time without changing false alarm rate. D-amphetamine reduced late $P N$ to location irrelevant stimuli and pitch irrelevant stimuli in both the attended and unattended location. The effect of $d$-amphetamine was interpreted as a decrease in the maintenance of the attentional trace to irrelevant stimuli. However, these changes were accompanied by some evidence of processing of stimulus features in the unattended location. These results suggest that $d$-amphetamine improves selective attention, and decreases the maintenance of attention to irrelevant

stimuli. [Neuropsychopharmacology 21:380-390, 1999] (C) 1999 American College of Neuropsychopharmacology. Published by Elsevier Science Inc.
KEY WORDS: D-amphetamine; Selective attention; ERPs; Processing negativity; P3

Selective attention is a process crucial to the efficient processing of sensory information, and involves the selection and processing of relevant sensory information, while rejecting irrelevant information from further processing. Event-related potentials (ERPs) provide a means by which it is possible to examine the on-line processing of relevant and irrelevant information during selective attention tasks. Unlike traditional behavioral indices of selective attention, ERPs can be elicited

From the National Drug and Alcohol Research Centre (RM, RPM, JRB) and School of Psychiatry (PBW, SVC), University of New South Wales, Sydney, Australia.

Address correspondence to: Rebecca McKetin, National Drug and Alcohol Research Centre, University of New South Wales, Sydney, NSW, 2052, Australia.

Received September 30, 1997; revised July 31, 1998; accepted August 25, 1998. by stimuli in the absence of a behavioral response, and consequently permit examination of how ignored stimuli are processed. ERPs also allow a detailed analysis of changes in processing across time from as early as 50 $\mathrm{ms}$ after the onset of the stimulus. This allows changes in sensory processing to be discriminated from the maintenance of attentional resources to a stimulus.

ERPs have been used to elucidate how the psychomimetic drug, amphetamine, affects processing of information. Studies using other paradigms, such as latent inhibition, suggest that amphetamine increases attentional resources to irrelevant stimuli and conscious processing of irrelevant stimuli in short term memory (Gray et al. 1992; Lubow and Gewirtz 1995; Solomon and Staton 1982; Weiner et al. 1981, 1984, 1988). ERP research has shown that d-amphetamine disrupts the sensory gating of auditory information that occurs $50 \mathrm{~ms}$ after the onset of the stimulus (Adler et al. 1986; Stevens et al. 1991). This result has been interpreted as disrup- 
tion of the pre-attentive filtering of irrelevant sensory information, and likened to the attentional dysfunction in schizophrenia. Disruption of pre-attentive filtering may increase load on conscious attention, increase the processing of irrelevant information, and interfere with the processing of relevant stimuli. It has not yet been established how amphetamine affects the later active selection and rejection of information. ERP potential indices of selective attention in humans provide a means for examining the effect of amphetamine on active selective attention and processing of auditory information.

Hansen and Hillyard (1983) developed a complex auditory selective attention task (CSAT) that has been used to elucidate mechanisms of selective attention in both clinical populations and healthy subjects (Hansen and Hillyard 1983; Karayanidis et al. 1995; Michie et al. 1990a, 1990b; Solowij et al. 1991, 1995). The CSAT requires subjects to make a button press response to deviant long duration tones with specified stimulus characteristics, presented amongst short tones that differ on dimensions of location (left vs. right ear) and pitch (low vs. high). The extent of negativity that occurs to short duration non-target tones (standards) has been interpreted as a measure of stimulus processing or allocation of attentional resources (Hansen and Hillyard 1983). This negativity has been termed processing negativity (PN), while the difference between $\mathrm{PN}$ to relevant and irrelevant inputs has been referred to as a negative difference $(\mathrm{Nd})$ wave. Large PN usually occurs to the standards that correspond to the target in terms of stimulus characteristics, while large PN occurring to irrelevant standards suggests a failure to reject these stimuli from further processing (Solowij et al. 1991, 1995). The temporal components of $\mathrm{PN}$ are thought to reflect different stages in processing the stimulus. Early PN (100270 ms post stimulus) represents the matching of stimulus features to a representation of the relevant stimulus in sensory memory (Näätänen 1982, 1990). This component overlaps with the N1 wave, thought to reflect processing of the sensory aspects of the stimulus (Näätänen and Michie 1979; Näätänen and Picton 1987). Late negativity (270-700 ms) represents controlled maintenance of attentional resources to the stimulus representation by an executive mechanism, in preparedness for further processing or responding (Näätänen 1990). Positivity (170-1000 ms) usually occurs to the standards presented in the irrelevant ear suggesting they are rejected in an early stage of processing (Michie et al. 1990a, 1993). Evaluation and processing of the target stimulus is indexed by amplitude and latency of the P3 component, which occurs to stimuli requiring a button press response (Hansen and Hillyard 1983).

The current study uses a version of the Hansen and Hillyard CSAT (location easy-pitch difficult) to investigate the effect of acute d-amphetamine on selective attention. D-amphetamine's effect on selective attention was assessed by comparing the PN elicited by relevant and irrelevant standards within each stimulus dimension (i.e., pitch and location). Two doses of d-amphetamine were tested, $10 \mathrm{mg}$ and $20 \mathrm{mg}$, which were compared to placebo using a within-subject repeated measures design. These doses were both considered to be within a low-moderate dose range for amphetamine, and it was expected that they would produce a linear dose effect. However, given the possibility that $10 \mathrm{mg}$ d-amphetamine would not affect selective attention or that doses may differentially affect selective attention, we also tested for non-linear drug effects.

It was hypothesised that if $d$-amphetamine increased processing of irrelevant information, $\mathrm{PN}$ to pitch and location irrelevant standards would be increased while PN elicited by the relevant standard that corresponded to the target stimuli in pitch and ear of delivery would be decreased. Decreased attention to task-relevant stimuli should impair detection of target stimuli and lead to decreased P3 amplitude. Increased responding to irrelevant stimuli would be reflected as an increased false alarm rate.

\section{METHOD}

\section{Subjects}

Subjects were 12 healthy paid volunteers ( 6 male, 6 females). Age ranged from 19 to 28 years (mean $=24$ years), weight $45-90 \mathrm{~kg}$ (mean $=68 \mathrm{~kg}$ ), and body mass index 19-28 $($ mean $=23.4)$. Subjects were excluded from the study if they reported: a) history of head trauma, unconsciousness, fits, convulsions, epileptic seizures, or attention deficit-hyperactivity disorder; $b$ ) a hearing or visual impairment that prevented completion of the tests; c) currently taking psychotropic medication; and d) contraindications to oral d-amphetamine ingestion. They were also excluded if they were at risk of experiencing medical complications from oral d-amphetamine or received a current DSM-III-R diagnosis of an Axis 1 psychiatric disorder, drug or alcohol dependence based on the computerised version of the Composite International Diagnostic Interview (1993) (CIDI-A). Two subjects were excluded from the study because they were unable to do the CSAT and a third subject was excluded on the basis of the medical examination. The study was approved by the Research Ethics Committee of the South East Sydney Area Health Service (Eastern Section) and the Committee on Experimental Procedures Involving Human Subjects (University of New South Wales).

\section{Design}

The study employed a repeated measures design whereby subjects were tested on four occasions in addition to the initial screening interview. Testing sessions 
took place approximately one week apart to ensure there were no carry over effects of $\mathrm{d}$-amphetamine from the previous week. The first testing session constituted a baseline recording to familiarise participants with the ERP procedure and to minimise practise effects on the later three testing sessions (Shelley et al. 1991). On the following three testing sessions subjects received either placebo, $10 \mathrm{mg}$ or $20 \mathrm{mg}$ of d-amphetamine 60 minutes prior to testing. Mood ratings, blood pressure and heart rate were measured before drug/placebo solutions were taken, prior to ERP testing (50 minutes after ingestion), midway through testing (80 minutes) and after testing (100 minutes). The amphetamine/placebo solutions were administered double blind, and the order of the drug/ placebo conditions counterbalanced using a Latin Square design.

\section{Procedure}

Subjects were screened over the telephone for suitability, and then underwent a further face-to-face screening interview prior to participation in the study. The screening interview involved confirmation of the telephone screening, de-briefing, obtaining consent, completing the computerised version of the Composite International Diagnostic Interview (CIDI-A), and obtaining weight and height measurements. Subjects also completed four runs of the CSAT, and were excluded from the study if their hit rate was below $50 \%$ or false alarm rate exceeded hit rate. Subjects were also examined by a medical practitioner and excluded from the study if they were at risk of experiencing medical complications from oral d-amphetamine.

Subjects were requested not to consume alcohol on the day of testing, and restrict intake on the day prior to testing, and refrain from using psychoactive drugs in the 24 hours prior to testing. This was confirmed by self-report prior to each test session and by drug screening urine samples obtained on each testing session. Subjects were also requested not to eat for at least one hour prior to testing. On arrival to the testing labora- tory subjects completed baseline mood ratings. Baseline blood pressure and heart rate were taken after the subject had been seated for several minutes. Subjects then drank a solution containing $50 \mathrm{ml}$ water, $5 \mathrm{ml}$ honey and either $125 \mathrm{mg}$ ascorbic acid (placebo), $10 \mathrm{mg}$ or 20 mg d-amphetamine (Sigma Pharmaceuticals). One hour after ingestion of the amphetamine/placebo solution subjects completed eight runs of the CSAT. Testing took place in a dimly lit, sound-attenuated, laboratory where subjects were seated in a semi-recumbent position.

\section{Auditory Selective Attention Task}

ERPs were recorded during a complex multidimensional auditory selective attention task (CSAT) (Hansen and Hillyard 1983). The design of the CSAT and the nomenclature used to describe stimulus attributes are depicted in Table 1. A random series of tones that varied on three dimensions: location (left vs. right ear); pitch (low [1047 Hz] vs. high [1319 Hz]) and duration (short [52 ms] vs. long [104 ms]); were presented through headphones (TDH 39). Seventy-six percent of the tones were short duration and $24 \%$ were long duration, or target tones. Subjects were required to button press to infrequent long duration tones of a particular location and pitch (targets) presented amongst the tones of other pitch, location and duration. Each run lasted $160 \mathrm{sec}-$ onds with 450 tones being presented at each location with a stimulus onset asynchrony (SOA) of 200-500 ms. Stimuli of each pitch and location were equally probable. Subjects completed eight runs in total, two runs for each attention condition, in a randomised order. Response hand was counterbalanced.

Responses were classified as correct if they occurred 200-1200 ms after presentation of a target stimulus. Reaction time was measured as the latency of the response from the onset of the target. Hit rate was calculated as a ratio of the total number of targets correctly identified. A miss was designated as any target not followed by a response (200-1200 ms post stimulus onset), and a false alarm a response to a non-target tone. The false alarm rate was calculated as a ratio of the total number of targets.

Table 1. Design of the Selective Attention Task (CSAT), and Stimulus Nomenclature

\begin{tabular}{|c|c|c|}
\hline & \multicolumn{2}{|c|}{ Location } \\
\hline & Satisfied $(50 \%)$ & Not Satisfied $(50 \%)$ \\
\hline \multicolumn{3}{|l|}{ Pitch } \\
\hline Satisfied (50\%) & $\begin{array}{l}\text { Long }(6.25 \%) \mathrm{L}+\mathrm{P}+\mathrm{D}+ \\
\text { Short }(18.75 \%) \mathrm{L}+\mathrm{P}+\mathrm{D}-\end{array}$ & $\begin{array}{l}\text { Long }(6.25 \%) \mathrm{L}-\mathrm{P}+\mathrm{D}+ \\
\text { Short }(18.75 \%) \mathrm{L}-\mathrm{P}+\mathrm{D}-\end{array}$ \\
\hline Not satisfied (50\%) & $\begin{array}{l}\text { Long }(6.25 \%) \mathrm{L}+\mathrm{P}-\mathrm{D}+ \\
\text { Short }(18.75 \%) \mathrm{L}+\mathrm{P}-\mathrm{D}-\end{array}$ & $\begin{array}{l}\text { Long }(6.25 \%) \mathrm{L}-\mathrm{P}-\mathrm{D}+ \\
\text { Short }(18.75 \%) \mathrm{L}-\mathrm{P}-\mathrm{D}-\end{array}$ \\
\hline
\end{tabular}

L, location (left vs. right ear); P, pitch (low vs. high); D, duration [short (standards) vs long (targets)]; '+', condition satisfied; ' - ' condition not satisfied; $\mathrm{L}+\mathrm{P}+\mathrm{D}+$, target stimulus to which subjects button press. 


\section{Event-Related Potentials}

The EEG was recorded from 21 scalp sites using an electrode cap (Electro-cap International) [Fp1, Fp2, Fz, F3, F4, F7, F8, Cz, C3, C4, Pz, P3, P4, T3, T4, T5, T6, L41, L42, W1, W2] with a nose reference. Vertical and horizontal EOG were recorded using tin electrodes placed above and below the left eye, and lateral to each eye, respectively. Resistance was less than $5 \mathrm{k} \Omega$ for all electrodes. EOG and EEG data were amplified with a band pass of $0.01-35 \mathrm{~Hz}$, and continuously digitised at 250 $\mathrm{Hz}$. Subjects were asked to fixate on a small green light and avoid blinking throughout the recording.

Overlapping epochs of $1280 \mathrm{~ms}$ ( $250 \mathrm{~ms}$ pre-stimulus to $1030 \mathrm{~ms}$ post-stimulus) were extracted from continuously digitised EEG recordings with epochs contaminated by eye blinks $( \pm 50 \mu \mathrm{V})$ automatically excluded during averaging. Epochs pertaining to each location were averaged separately for both long (target) and short (standard) duration stimuli and were denoted as follows: $\mathrm{L}+$ attended location; $\mathrm{L}-$ unattended location; $\mathrm{P}+$ relevant pitch; $\mathrm{P}-$ irrelevant pitch; $\mathrm{D}+$ long duration (targets); D- short duration (standards). Peak amplitudes were calculated using an automatic peak detection program (SCAN 4.0) that identified the maximal value of designated polarity within a given time window. The time windows used in this analysis were: P1 (0-100 ms), N1 (50-150 ms), P2 (150-350 ms), P3 (300-800 ms). Mean amplitudes for each of the standard waveforms were computed for three epochs: 100-260 ms, 260-400 $\mathrm{ms}, 400-800 \mathrm{~ms}$. The first epoch approximates the previously described early PN (Michie et al. 1993; Näätänen 1982, 1990; Näätänen and Michie 1979), and the second two together encompass late PN (Michie et al. 1993; Näätänen and Michie 1979) which was measured separately to provide an index of late PN that was not influenced by the $\mathrm{P} 2$ peak.

\section{Mood Ratings}

Mood was assessed with the Amphetamine Mood Questionnaire (AMQ): a questionnaire devised specifically for this study. It was based on the self-report of illicit amphetamine users (Topp et al. 1995) and was validated against the Morphine/Benzedrine Group (MBG) scale of the Addiction Research Center Inventory (ARCI) (Haertzen and Hickey 1987). The ARCI-MBG scale describes only the hedonic or appetitive state produced by amphetamine. In contrast, the AMQ consisted of two scales, one reflecting amphetamine "like" effects (amphetamine-like scale), and the second representing amphetamine 'opposite' effects (amphetamine-opposite scale), that is "come-down" or withdrawal symptoms. Each of the 19 items are rated on a 5 point Likert scale, yielding a score of 0-4 (McKetin et al. 1996).

\section{Data Analysis}

ERP Indices. ERP indices were analysed by repeated measures ANOVA (SPSS, version 6.1) using Greenhouse-Geisser epsilon correction for sphericity (Vasey and Thayer 1987). Lateral electrodes sites were analysed using a hemisphere [left vs. right] by electrode plane [prefrontal vs. frontal vs. central] by drug [0, 10 or $20 \mathrm{mg}$ d-amphetamine] design. Anterior-posterior differences in ERP indices were analysed at midline electrodes using an electrode site [Fz vs. Cz] by drug design. $\mathrm{P} 3$ amplitude was examined at parietal $[\mathrm{P} 3, \mathrm{Pz}$, $\mathrm{P} 4]$ and central [C3, Cz, C4] electrode sites. Interaction effects between d-amphetamine and electrode plane effects at lateral sites [prefrontal, frontal, central] were carried out in conjunction with d-amphetamine dose comparisons (see D-amphetamine Dose Effect). A linear trend contrast $\left[\begin{array}{lll}-1 & 0 & 1\end{array}\right]$ was used to indicate the anterior-posterior direction of the effect and a quadratic trend contrast [ $1-21]$ was used to test for an effect at the frontal plane only, where PN effects are maximal. Spearman correlations were used to examine the relationship between ERPs affected by d-amphetamine and performance measures. To facilitate presentation of results, only significant effects are presented unless otherwise stated.

D-amphetamine Dose Effect. The effect of d-amphetamine dose was examined using four planned contrasts: a) placebo vs. both $10 \mathrm{mg}$ d-amphetamine and 20 mg d-amphetamine [2-1-1]; b) a linear trend dose effect [1 $0-1]$; c) an effect of $10 \mathrm{mg}$ d-amphetamine but not $20 \mathrm{mg}$ d-amphetamine [ $-12-1]$ (quadratic contrast) to test the possibility that amphetamine has a non-linear dose effect; and d) a dose threshold effect whereby $20 \mathrm{mg}$ $\mathrm{d}$-amphetamine but not $10 \mathrm{mg}$ d-amphetamine had an effect $\left[\begin{array}{lll}-1 & -12\end{array}\right]$. Placebo and $10 \mathrm{mg}$ conditions were grouped together in the last contrast to test if these conditions were equivalent, with effects only observed following the $20 \mathrm{mg}$ dose. Quadratic trend for d-amphetamine dose was not tested on physiological indices because there was no rationale for expecting larger physiological changes with $10 \mathrm{mg}$ than $20 \mathrm{mg}$ d-amphetamine. Interactions repeated physiological measures (baseline, pre-test, post-test) and d-amphetamine dose were analysed using six contrasts that tested overall d-amphetamine effect $[2-1-1]$ and linear dose effect [ $\left.\begin{array}{lll}1 & 0 & -1\end{array}\right]$ with three time comparisons: a) baseline vs. pre-test and post-test [2-1-1], b) linear increase in effect with time [ -101$], c)$ and a quadratic trend to test if d-amphetamine induced changes had dissipated at post-test [1 - 21$]$. All follow-up contrasts were carried out using the error term specific to each contrast, controlling the type one error rate even when the assumption of sphericity was violated (Boik 1981; Maxwell 1980). Analysis of performance, mood and physiological data employed only planned contrasts and con- 
trolled family-wise error rate at .05 using Bonferroni adjustment.

\section{RESULTS}

\section{Mood Changes}

Mood ratings (AMQ) at baseline and following either placebo, $10 \mathrm{mg}$ or $20 \mathrm{mg}$ can be seen in Figure 1 . Changes in 'amphetamine-like' (A) and 'amphetamineopposite' (B) mood ratings were analysed separately. Mood change was measured as the difference between pre-test and baseline rating. Post ingestion ratings taken at 100 minutes were excluded from the analysis because mood changes were confounded by experimentation that took place between the 50 and 100 minute interval. Subjects showed a significant increase in amphetamine-like affect ratings 50 minutes following amphetamine administration $\left(F_{0.05 / 4}(1,11)=49.3, p<\right.$ $.01)$. The increase in amphetamine-like affect was found to be linearly related to the dose of amphetamine $\left(F_{0.05 / 4}\right.$ $(1,11)=39.7, p<.01)$. Amphetamine-opposite affect
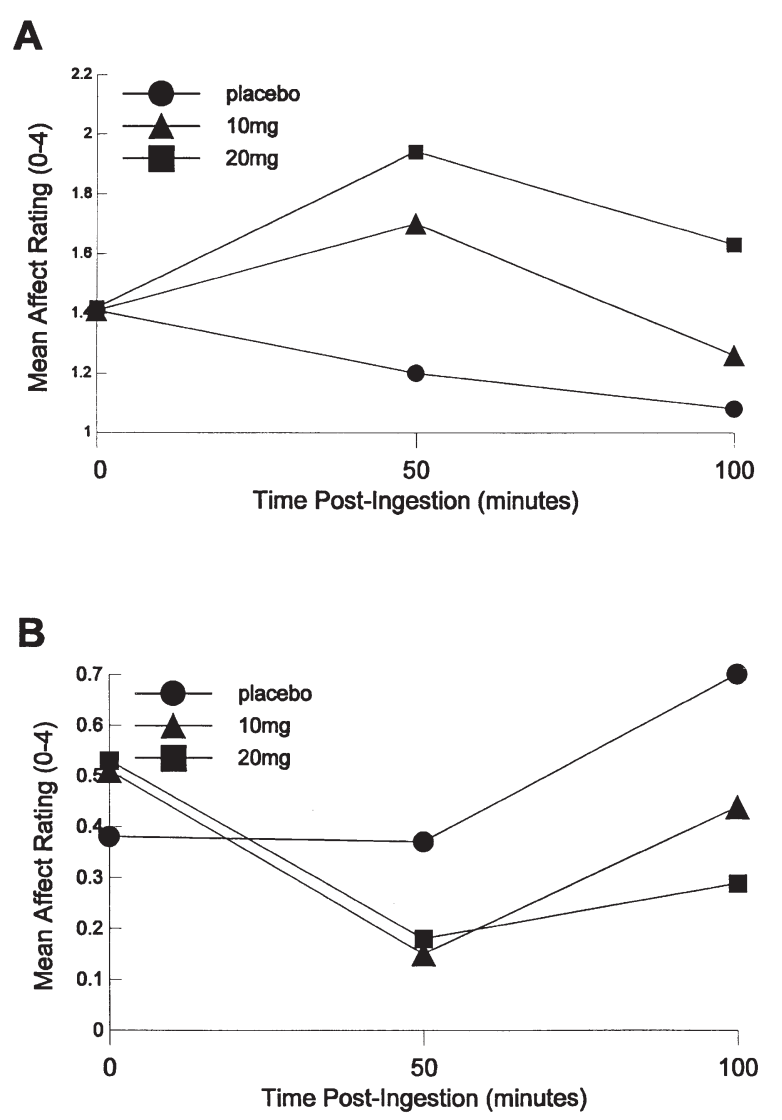

Figure 1. Change in ratings on the amphetamine-like (A) and amphetamine-opposite (B) scales of the Amphetamine Mood Questionnaire at baseline (0 $\mathrm{min})$, pre-test $(50 \mathrm{~min})$ and post-test $(100 \mathrm{~min})$ following either placebo, $10 \mathrm{mg}$ or 20 mg of d-amphetamine. was significantly decreased following amphetamine administration $\left(F_{0.05 / 4}(1,11)=11.6, p<.05\right)$, however, this effect was not as large as for the amphetamine-like affect. Nor was there a dose response relationship $\left(F_{0.05 / 4}\right.$ $(1,11)=3.9, n s)$.

\section{Physiological Changes}

Table 2 shows mean blood pressure and heart rate across testing for the three conditions: placebo, $10 \mathrm{mg}$ and $20 \mathrm{mg}$ d-amphetamine. D-amphetamine produced a linear dose-related increase in systolic and diastolic blood pressure relative to placebo conditions. Diastolic pressure increased throughout testing $\left(F_{0.05 / 6}(1,11)=\right.$ $11.95, p<.05)$, while systolic pressure showed an overall post-drug effect $\left(F_{0.05 / 6}(1,11)=13.5, p<.05\right)$. $\mathrm{D}$-amphetamine also produced a dose response increase in heart rate relative to the placebo condition $\left(F_{0.05 / 6}(1,11)=17.57, p<.01\right)$. All physiological indices remained reasonably constant across testing, showing no significant drop at post-test $(F<1)$.

\section{Performance}

Amphetamine was found to enhance performance on the CSAT, increasing hit rate $\left(F_{0.05 / 4}(1,11)=9.69, p<\right.$ $.05)$ and decreasing reaction time $\left(F_{0.05 / 4}(1,11)=10.77\right.$, $p<.05)$. A dose response relationship (linear trend) was observed for d-amphetamine's effect on both hit rate $\left(F_{0.05 / 4}(1,11)=17.07, p<.01\right)$ and reaction time $\left(F_{0.05 / 4}(1,11)=9.33, p<.05\right)$ (see Table 3$)$. There was no significant difference in error rate between the three conditions (placebo, $10 \mathrm{mg}$ and $20 \mathrm{mg}$ dexamphetamine) $(F<1)$. This suggests that the increased hit rate with amphetamine was not due to subjects using a more liberal response criterion.

\section{ERPs to Target Stimuli}

D-amphetamine produced a significant increase in P3 amplitude at the vertex (see Figure 2); however, this effect was restricted to the $\mathrm{Cz}$ electrode $(F(2,10)=3.6$, $p<.04)$ and occurred following $20 \mathrm{mg}$ d-amphetamine only $(F(1,11)=6.6, p<.05)$. There was no significant effect of d-amphetamine of $\mathrm{P} 3$ amplitude at lateral electrode sites $(F(2,10)=0.6-1.8, p<.19)$. D-amphetamine did not significantly affect latency to peak P3 amplitude at either vertex or lateral sites.

\section{ERPs to Standards}

ERP waveforms for standard stimuli at frontocentral sites [F3, Fz, F4] are shown in Figure 2. D-amphetamine produced a reduction in N1 amplitude to standard stimuli and also appeared to reduce late $\mathrm{PN}$ to pitchirrelevant standards in both the attended and unat- 
Table 2. Blood Pressure and Heart Rate Following Placebo, $10 \mathrm{mg}$ or $20 \mathrm{mg}$ d-amphetamine: Mean (SD)

\begin{tabular}{llll}
\hline & \multicolumn{3}{c}{ Condition } \\
\cline { 2 - 4 } & Placebo & $\mathbf{1 0 ~} \mathbf{~} \mathbf{g}$ & $\mathbf{2 0 ~} \mathbf{~ m g}$ \\
\hline Blood pressure (diastolic/systolic) & & & \\
Baseline & $119 / 70$ & $121 / 72$ & $116 / 64$ \\
& $(15)(7)$ & $(17)(11)$ & $(18)(21)$ \\
Pre-test & $116 / 72$ & $125 / 75$ & $129 / 77$ \\
& $(16)(11)$ & $(11)(12)$ & $(12)(9)$ \\
Post-test & $117 / 71$ & $125 / 77$ & $129 / 79$ \\
& $(13)(8)$ & $(13)(8)$ & $(15)(9)$ \\
Heart rate (per minute) & & & $67(22)$ \\
Baseline & $73(11)$ & $71(15)$ & $77(17)$ \\
Pre-test & $66(11)$ & $72(13)$ & $76(12)$ \\
Post-test & $64(10)$ & $73(8)$ & \\
\hline
\end{tabular}

tended location. Decreased PN to pitch-irrelevant stimuli suggests improved ability to ignore irrelevant information. The separation between PN to pitch-relevant and pitch-irrelevant stimuli in the unattended location suggests that subjects on d-amphetamine were processing pitch features in the unattended ear. This is indicative of a more exhaustive or independent strategy for processing stimulus features (Hansen and Hillyard 1983).

N1 amplitude D-amphetamine produced a significant reduction in $\mathrm{N} 1$ amplitude to all standard stimuli at both midline $(F(2,10)=9.11, p<.001)$ and lateral $(F(2,10)=$ $9.3, p<.001)$ electrode sites. Linear trend contrasts indicated that $\mathrm{N} 1$ amplitude reduction was dose dependent (midline: $F(1,11)=18.7, p<.001$; lateral: $F(1,11)=16.1$, $p<.001)$. There was no significant change in latency to peak N1 amplitude following either 10 or $20 \mathrm{mg}$ d-amphetamine.

Early PN. D-amphetamine had no significant effect on early PN (100-260 ms and 260-400 ms epochs).

Late PN. There was a significant interaction at midline electrode sites between d-amphetamine and pitch, that depended on electrode plane $(F(2,10)=4.3, p<.03)$. Follow-up contrasts confirmed that d-amphetamine produced a linear increase in PN separation between relevant and irrelevant pitch at the Fz site that did not depend on location $(F(1,11)=8.1, p<.03)$ (see Figure
3). This was due to a decrease in $\mathrm{PN}$ to pitch-irrelevant stimuli (Placebo $=-0.06 \pm 0.13,10 \mathrm{mg}=0.30 \pm$ $0.26,20 \mathrm{mg}=0.53 \pm 0.20)$ relative to pitch-relevant stimuli (Placebo $=-0.30 \pm 0.26,10 \mathrm{mg}=-0.07 \pm 0.14$, $20 \mathrm{mg}=-0.28 \pm 0.20)$. The effect of d-amphetamine on PN to pitch irrelevant standards was not significant at the lateral electrode sites $(F(2,10)=2.3, p<.12)$. There was also a significant interaction between location, electrode plane and drug at lateral electrode sites $(F(2,10)=3.3$, $p<.04)$. Follow-up tests revealed increased separation between location-relevant and location-irrelevant standards in the $10 \mathrm{mg}$ condition that was largest at $\mathrm{C} 3$ and C4 electrode sites $(F(1,11)=9.5, p<.01)$ (see Figure 4). This effect was due to decreased $\mathrm{PN}$ to location irrelevant stimuli (Placebo $=-0.28 \pm 0.22,10 \mathrm{mg}=0.44 \pm 0.26,20$ $\mathrm{mg}=-0.05 \pm 0.18)$ relative to stimuli in the attended location (Placebo $=-0.53 \pm 0.14,10 \mathrm{mg}=-0.38 \pm 0.17,20$ $\mathrm{mg}=-0.36 \pm 0.16$ ). The effect of $\mathrm{d}$-amphetamine on PN to location irrelevant stimuli was not significant at midline electrode sites $(F(2,10)=5.0, p<.07)$.

\section{Relationship Between Performance and ERPs}

Increased P3 amplitude was correlated with increased hit rate $\left(\mathrm{r}_{\mathrm{s}}=0.47 p<.01\right)$, and decreased reaction time $\left(\mathrm{r}_{\mathrm{s}}=-0.65 p<.001\right)$. This relationship between reaction time and P3 amplitude can be seen in Figure 5. Reaction time and hit rate were not related to other

Table 3. Performance on the CSAT Following Either Placebo, 10 or $20 \mathrm{mg}$ d-amphetamine: Mean (SD)

\begin{tabular}{lccc}
\hline & $\begin{array}{c}\text { Hit Rate } \\
\mathbf{( \% )}\end{array}$ & $\begin{array}{c}\text { False } \\
\text { Alarms } \\
\mathbf{( \% )}\end{array}$ & $\begin{array}{c}\text { Reaction } \\
\text { Time } \\
(\mathbf{m s})\end{array}$ \\
\hline Placebo & $81(11.0)$ & $3.0(1.8)$ & $524(86.8)$ \\
$10 \mathrm{mg}$ d-amphetamine & $85(8.5)$ & $2.8(0.9)$ & $500(83.4)$ \\
$20 \mathrm{mg}$ d-amphetamine & $88(6.7)$ & $3.1(1.3)$ & $483(59.7)$ \\
\hline
\end{tabular}




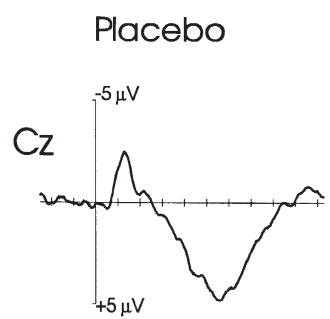

Targets $(L+P+D+)$
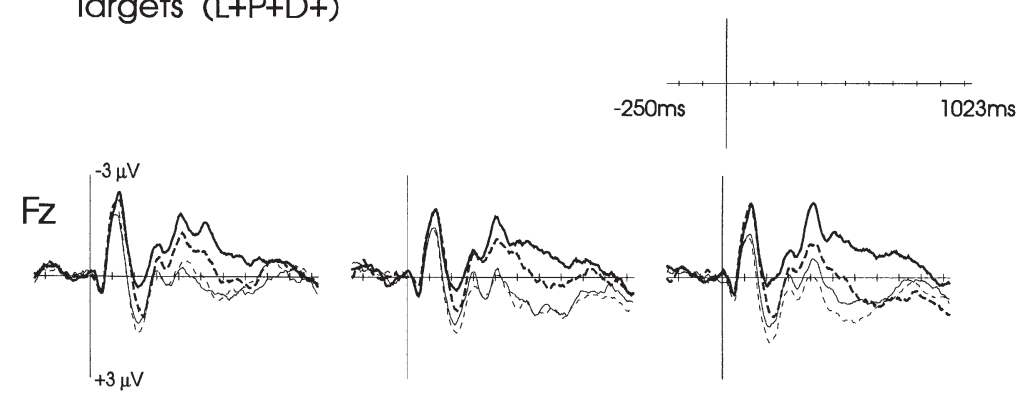

Standards

\section{$10 \mathrm{mg}$ d-amphetamine}

\section{$20 \mathrm{mg}$}

d-amphetamine
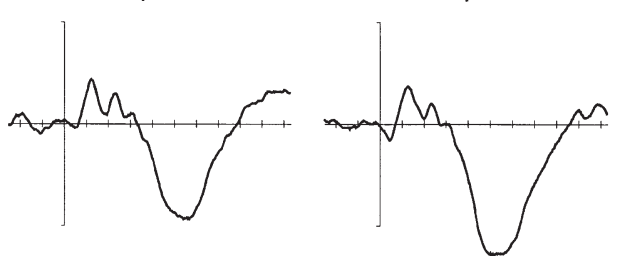

Figure 2. Grand mean ERPs for target stimuli $(\mathrm{L}+\mathrm{P}+\mathrm{D}+)$ at $\mathrm{Cz}$ and standard stimuli $(\mathrm{D}-)$ at $\mathrm{Fz}$ following either placebo, $10 \mathrm{mg}$ or $20 \mathrm{mg}$ d-amphetamine. amphetamine induced changes in ERPs, namely N1 amplitude $\left(\mathrm{r}_{\mathrm{s}}=-0.08\right.$ to $\left.0.05, p>.65\right)$, decreased PN to location irrelevant $\left(\mathrm{r}_{\mathrm{s}}=-0.09\right.$ to $\left..15, p>.37\right)$ or pitch irrelevant $\left(\mathrm{r}_{\mathrm{s}}=-0.05\right.$ to $\left.-0.06, p<.70\right)$ standards.

\section{DISCUSSION}

D-amphetamine improved performance on the CSAT, producing a linear dose response increase in hit rate and decrease in reaction time. These changes occurred without any change in false alarm rate, indicating that increased hit rate was not due to subjects adopting a more liberal response bias. ERPs showed that d-amphetamine decreased late PN to irrelevant stimuli, without changing PN to the relevant stimulus. This result indicates that subjects on d-amphetamine are less likely to maintain an attentional trace to irrelevant auditory stimuli. D-amphetamine also increased P3 amplitude, which was correlated with improved performance, suggesting improved recognition of the target stimulus. These results suggest that d-amphetamine improves recognition of the relevant target stimulus, and decreases attention to irrelevant stimuli.

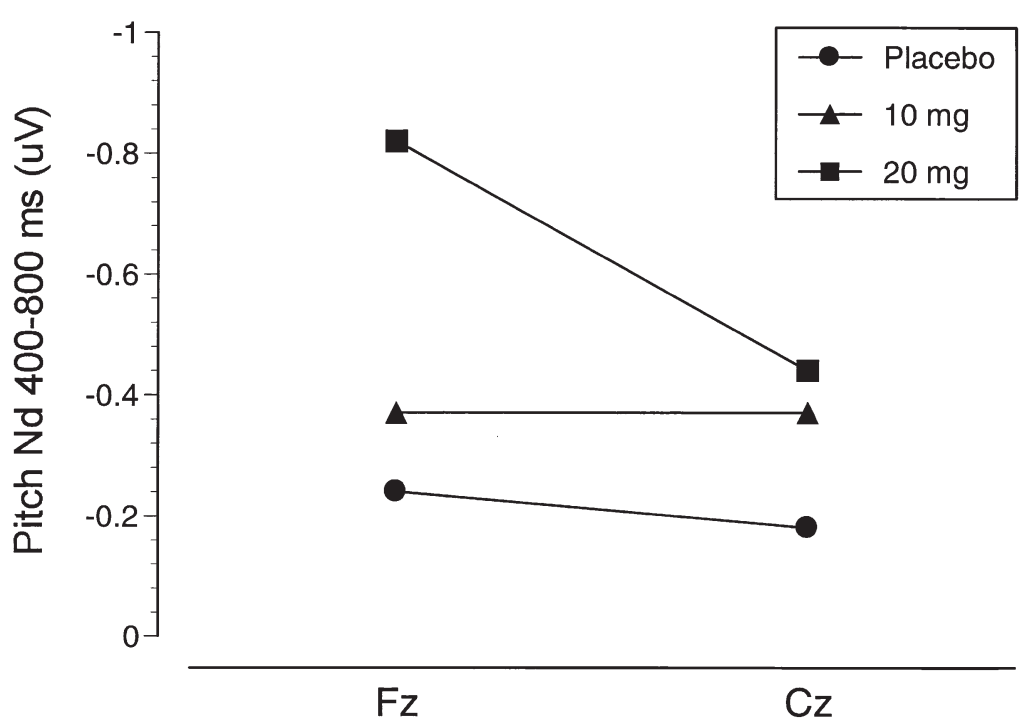

Figure 3. Mean pitch Nd (separation between PN to pitch-relevant and pitch-irrelevant standards) $400-800 \mathrm{~ms}$ post-stimulus at the Fz electrode sites for placebo, $10 \mathrm{mg}$ and $20 \mathrm{mg}$ d-amphetamine conditions. 


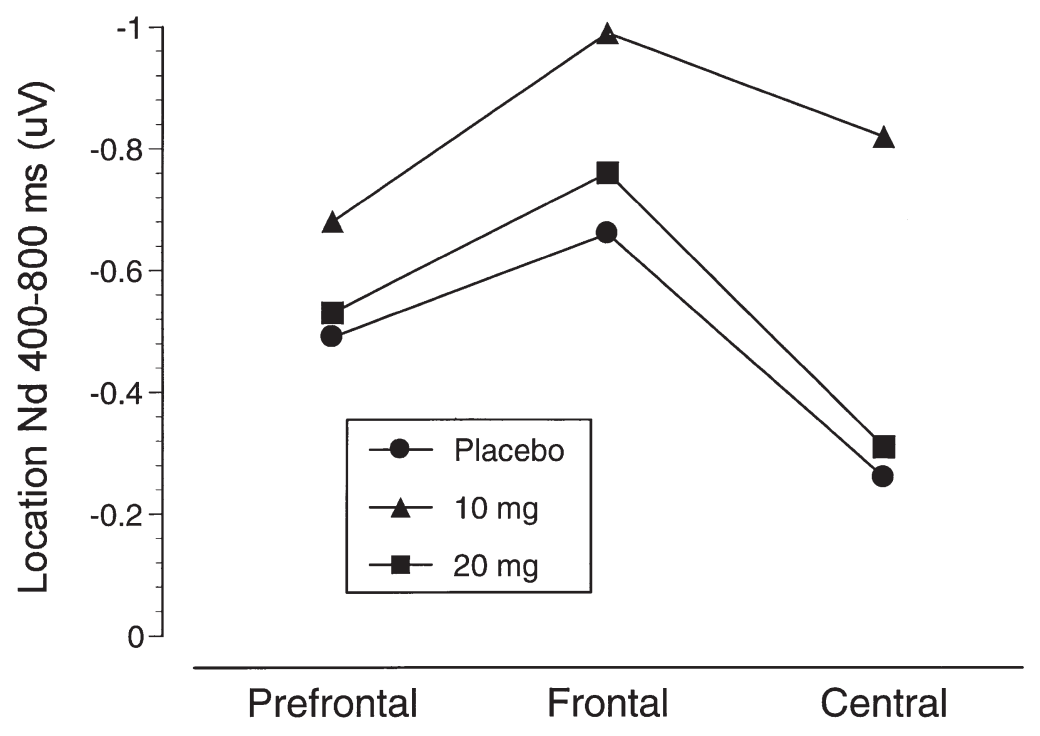

Figure 4. Mean location Nd (separation between PN to location-relevant and location-irrelevant standards) 400-800 ms post-stimulus at lateral electrode (mean of Fp1 and Fp2, F3 and F4, C3 and C4) sites for placebo, $10 \mathrm{mg}$ and $20 \mathrm{mg}$ d-amphetamine conditions.

\section{Early Sensory Processing}

D-amphetamine reduced N1 amplitude to standard stimuli, indicating reduced sensory sensitivity (Bak et al. 1985) or reduced attention (Näätänen et al. 1992) to standard stimuli. Decreased N1 amplitude is unlikely to be due to attentional modulation of this component, because N1 amplitude was not differentially affected by the relevance of the stimulus. In addition, there was no change in early PN, which usually accompanies attentional modulation of the N1 component (Näätänen and Michie 1979; Näätänen and Picton 1987; Näätänen et al. 1992; for an alternative explanation see Woldorff and Hillyard 1991). Reduced N1 amplitude following d-amphetamine is consistent with Stevens et al. (1991) who found d-amphetamine attenuated auditory evoked potentials during an auditory gating task. D-amphetamine could reduce sensory sensitivity to auditory stimuli by modulating activity of the supratemporal plane of the auditory cortex, the region thought to be responsible for the propagation of a frontocentral N1 wave to auditory stimuli (Näätänen and Picton 1987; Knight et al. 1988).

\section{Maintenance of Attention}

D-amphetamine decreased maintenance of the attentional trace to irrelevant stimuli without affecting attention to the relevant stimulus. More specifically, d-amphetamine reduced late PN to location irrelevant stimuli and pitch irrelevant stimuli in both the attended and unattended location. Although these changes indicate that d-amphetamine reduced attention to irrelevant stimuli, decreased $\mathrm{PN}$ to pitch irrelevant stimuli in the unattended location suggests subjects were unnecessarily processing the pitch of stimuli in the unattended ear. This result ostensibly suggests an inefficient exhaustive processing

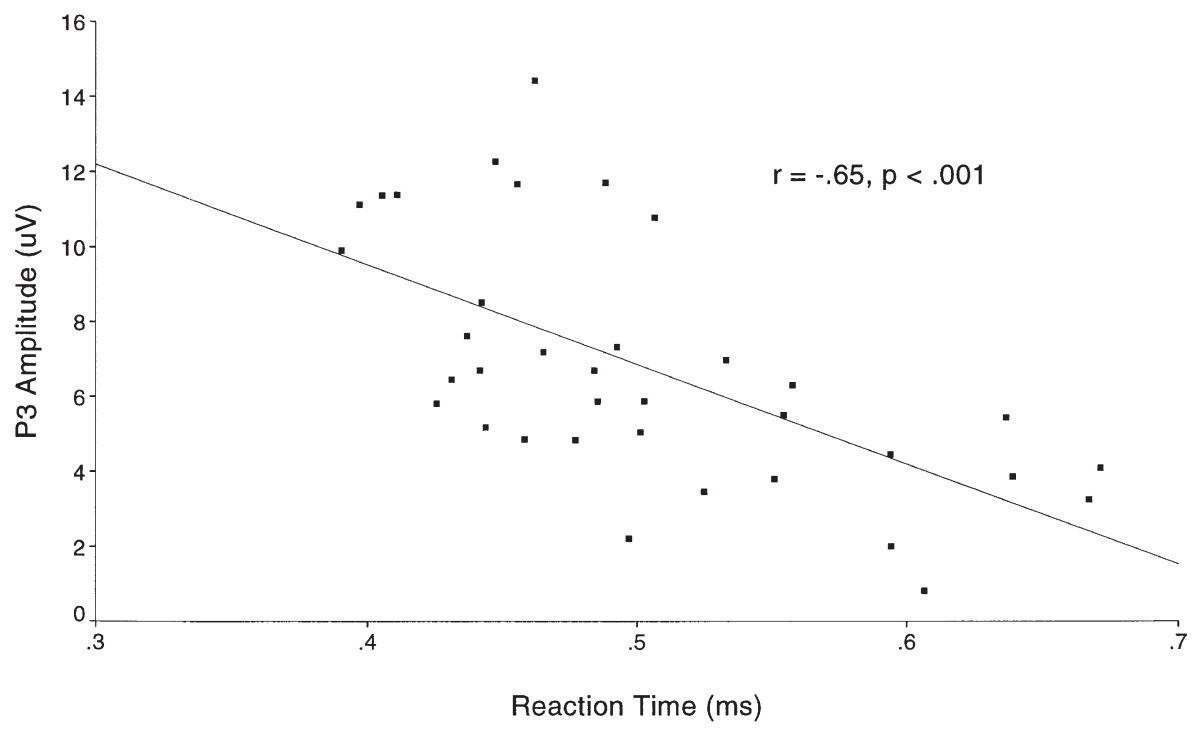

Figure 5. Relationship between reaction times (ms) and P3 amplitude $(\mu \mathrm{V})$ at the $\mathrm{Cz}$ electrode site. 
strategy (Hansen and Hillyard 1983), and may reflect a deficit in the early sensory filtering of irrelevant auditory information. If this was the case, increased pitch separation in the unattended ear should have also been apparent in the earlier PN (100-260 ms), which is thought to reflect the selection of the relevant stimulus channel (Näätänen 1990). The fact that d-amphetamine did not alter early changes in PN suggests that the late PN pitch separation in the unattended ear does not reflect a deficit in the early filtering processes. A deficit in sensory filtering would also be expected to increase demand on conscious attentional resources, increase attention to irrelevant information, decrease attentional resources available to process relevant stimuli, and impair performance. To the contrary, d-amphetamine decreased PN to irrelevant stimuli, did not impair attention to relevant stimuli, and improved performance. An alternative explanation for spreading of attentional resources to the unattended ear is that amphetamine somehow reduced the attentional resources needed to undertake the necessary elements of the CSAT. Kahneman (1973) theorised that attentional resources can be actively distributed among tasks, depending on demand, and attentional resources not needed to perform one task can be devoted to processing irrelevant information. This explanation for pitch processing in the unattended ear is consistent with the late onset of the effect, which corresponds to conscious rather than pre-conscious allocation of attentional resources (Näätänen 1990). It also explains why pitch processing in the unattended ear did not interfere with processing of the relevant stimuli or detection of the target stimuli. One way that d-amphetamine could have reduced the attentional resources necessary to complete the CSAT is by improving auditory discrimination. Hansen and Hillyard (1983) showed that reducing the difficulty of pitch and location discrimination in the CSAT not only reduced processing of pitch irrelevant stimuli but also increased PN separation between pitch relevant and irrelevant standards in the unattended locations, a pattern similar to that seen following d-amphetamine. Thus, d-amphetamine may have produced similar ERP changes to those seen with the easier version of the CSAT by reducing the difficulty of channel discrimination. Improved auditory discrimination is consistent with the increase in $\mathrm{P} 3$ amplitude produced by d-amphetamine, suggesting improved target detection (Hansen and Hillyard 1983; Paul and Sutton 1972) and previous evidence that $\mathrm{d}$-amphetamine improves signal detection (Koelega 1993).

The present findings suggest that amphetamine does not impair the active selection of relevant from irrelevant information, and does not impair ability to maintain attention to relevant stimuli while ignoring competing stimuli. The failure of d-amphetamine to disrupt selective attention suggests that any early changes in sensory gating or filtering of irrelevant sensory information produced by amphetamine do not impair the later selection and processing of relevant stimuli. This is contrary to what would be expected if amphetamine produced conscious processing of irrelevant information. This discrepancy may reflect the nature of the CSAT compared to filtering paradigms such as latent inhibition and sensory gating. The CSAT involves active selection of discrete auditory stimuli, and does not measure pre-attentive processes or contextual learning which are fundamental to the auditory gating and latent inhibition paradigms. The different effects of d-amphetamine on auditory selective attention and latent inhibition, also suggests that findings about the processing of irrelevant information obtained from these paradigms may not generalise to selective attention.

\section{Relationship to Schizophrenic Attention Dysfunction}

Amphetamine has been used to model schizophrenic attentional dysfunction (Feldon and Weiner 1991; Gray et al. 1991; Lubow and Gewirtz 1995; Solomon et al. 1981). The current study shows that acute d-amphetamine produces very different changes in the CSAT to those seen in unmedicated schizophrenics. D-amphetamine increased P3 amplitude and improved performance, whereas schizophrenics showed decreased P3 amplitude and less accurate performance (McConaghy et al. 1993; Michie et al. 1990b; Ward et al. 1991). The discrepancy between the effects of d-amphetamine in the present study and attentional changes found in schizophrenia, questions the assumption that acute d-amphetamine produces the same attentional dysfunction as that seen in psychosis. This discrepancy probably reflects the qualitative difference between the changes in dopamine activity following a single dose of d-amphetamine and those associated with amphetamine-induced psychosis. Dose regimes of amphetamine typically required to produce psychosis (Angrist and Gershon 1970; Ellinwood 1971; Griffith et al. 1972) may alter dopaminergic regulation and have neurotoxic effects, aside from increasing dopamine activity (Fields et al. 1991; Ricaurte et al. 1984a,b). A single low dose of amphetamine might not mimic either the changes in catecholamine functioning or the attentional dysfunction present in psychosis.

Consistent with this, Shelley et al. (1997) found that decreasing dopamine levels by droperidol administration produced a similar pattern of ERP changes to those seen in unmedicated schizophrenics. This is contrary to the notion that excessive dopamine activity is thought to be responsible for disrupted selective attention in schizophrenia. Shelley et al. (1997) reconciled this contrary finding by postulating that dopamine activity has a $U$ shaped relationship with selective attention, whereby, 
either underactivity or overactivity disrupts selective attention. However, the present study shows that increasing dopamine levels, albeit in conjunction with increased noradrenaline levels, improved rather than impaired selective attention during the CSAT.

\section{CONCLUSION}

In summary, d-amphetamine improved performance on the location easy-pitch difficult version of Hansen and Hillyard's (1983) CSAT, by increasing hit rate and speeding reaction time. D-amphetamine decreased the maintenance of attention resources to irrelevant stimuli and improved detection of the relevant target stimulus. These findings suggest that $\mathrm{d}$-amphetamine-induced deficits in auditory filtering (Adler et al. 1986; Stevens et al. 1991) do not manifest as impairments in the later active selective and rejection of auditory stimuli. These findings are inconsistent with the notion that d-amphetamine produces conscious processing of irrelevant information in short term memory (Lubow and Gewirtz 1995), or impairs ability to ignore irrelevant stimuli (Feldon and Weiner 1991). Changes in auditory selective attention following d-amphetamine were discrepant with those found in unmedicated schizophrenics, suggesting acute doses of d-amphetamine do not mimic the attention dysfunction in schizophrenia.

\section{ACKNOWLEDGMENTS}

This research was funded by a New South Wales Department of Health, Drug and Alcohol Directorate Post Graduate Scholarship and was conducted at the Prince of Wales Hospital, Sydney, Australia in collaboration with the Biological Schizophrenia Research Team. The authors thank John Lewis and the Royal North Shore Hospital Toxicology Unit for conducting drug screens on urine samples, Richard Peters for his assistance in the double blind administration of drug solutions, and Mark Pearson for technical assistance.

\section{REFERENCES}

Adler LE, Rose G, Freedman R (1986): Neurophysiological studies of sensory gating in rats: Effects of amphetamine, phencyclidine and haloperidol. Biol Psychiatry 21:787-798.

Angrist BM, Gershon S (1970): The phenomenology of experimentally induced amphetamine psychosis preliminary observations. Biol Psychiatry 2:95-107

Bak CK, Lebech J, Saermark K (1985): Dependence of the auditory evoked magnetic field (100 min signal) of the human brain on the intensity of the stimulus. Electroencephalogr Clin Neurophysiol 61:141-149

Boik RJ (1981): A priori tests in repeated measures designs: Effects of nonsphericity. Psychometrika 46:241-255
Composite International Diagnostic Interview-Auto (Version 1.1) [Computer Software] (1993): Training and Reference Centre for WHO and CIDL. Sydney, Australia, World Health Organisation.

Ellinwood EH (1971): Assault and homicide associated with amphetamine abuse. Am J Psychiatry 127:1170-1175

Feldon J, Weiner I (1991): The latent inhibition model of schizophrenic attention disorder, Haloperidol and sulpuride enhance rat's ability to ignore irrelevant stimuli. Biol Psychiatry 29:635-646

Fields JZ, Wichlinski L, Drucker GE, Engh K, Gordon JH (1991): Long-lasting dopamine receptor up-regulation in amphetamine treated rats following amphetamine neurotoxicity. Pharmacol Biochem Behav 40:881-886

Gray JA, Feldon J, Rawlins JNP, Hemsley DR, Smith AD (1991): The neuropsychology of schizophrenia. Behav Brain Sci 14:1-84

Gray NS, Pickering AD, Hemsley DR, Dawling S, Gray JA (1992): Abolition of latent inhibition by a single $5 \mathrm{mg}$ dose of $\mathrm{d}$-amphetamine in man. Psychopharmacol 107:425-430

Griffith JD, Cavanaugh J, Held J, Oates JA (1972): Dextroamphetamine: Evaluation of psychomimetic properties in man. Arch Gen Psychiatry 26:97-100

Haertzen CA, Hickey JE (1987): Addiction Research Center Inventory (ARCI): Measurement of euphoria and other drug effects. In Bozarth MA (ed), Methods of Assessing the Reinforcing Properties of Abused Drugs. New York, Springer-Verlag, pp 489-524

Hansen JC, Hillyard SA (1983): Selective attention to multidimensional auditory stimuli. J Exp Psychol (Hum Percept) 9:1-19

Kahneman D (1973): Attention and Effort. Englewood Cliffs NJ, Prentice-Hall

Karayanidis F, Andrews S, Ward PB, Michie PT (1995): ERP indices of auditory selective attention in aging and Parkinson's disease. Psychophysiology 32:335-350

Koelega HS (1993): Stimulant drugs and vigilance performance: A review. Psychopharmacol 111:1-16

Knight RT, Scabini D, Woods DL, Clayworth C (1988): The effects of lesions of superior temporal gyrus and inferior parietal lobe on temporal and vertex components of the human AEP. Electroencephalogr Clin Neurophysiol 70:499-509

Lubow RE, Gewirtz JC (1995): Latent inhibition in humans: Data, theory, and implications for schizophrenia. Psychol Bull 117:87-103

Maxwell SE (1980): Pairwise multiple comparisons in repeated measures designs. J Educ Statistics 5:269-287

McKetin R, Mattick RP, Ward PB, Catts SV, Bell JR (1996): Amphetamine use: Changes in mood, memory and attention. In Topp L and Dillon P (eds), Looking to the Future: A Second Generation of Drug Research. NDARC Monograph No. 29: Proceedings from the 10th National Drug and Alcohol Research Centres Annual Symposium, pp 31-45

McConaghy N, Catts SV, Michie PT, Fox A, Ward PB, Shelley A-M (1993): P300 indexes thought disorder in schizophrenics, but allusive thinking in normal subjects. J Nerv Ment Dis 181:176-182 
Michie PT, Bearpark HM, Crawford JM, Glue LCT (1990a): The nature of selective attention effects on auditory event-related potentials. Biol Psychol 30:219-250

Michie PT, Fox AM, Ward PB, Catts SV, McConaghy N (1990b): Event-related potential indices of selective attention and cortical lateralization in schizophrenia. Psychophysiology 27:209-227

Michie PT, Solowij N, Crawford JM, Glue L (1993): The effects of between-source discriminability on attended and unattended auditory ERPs. Psychophysiology 30:205-220

Näätänen R (1982): Processing negativity: An evoked-potential reflection of selective attention. Psychol Bull 92:605-640

Näätänen R (1990): The role of attention in auditory information processing as revealed by event-related potentials and other brain measures. Behav Brain Sci 13:201-288

Näätänen R, Michie PT (1979): Early selective attention effects on the evoked potential. A critical review and reinterpretation. Biol Psychiatry 8:81-136

Näätänen R, Picton T (1987): The N1 wave of the human electric and magnetic response to sound: A review and an analysis of the component structure. Psychophysiology 24:375-425

Näätänen R, Teder W, Alho K, Lavikainen J (1992): Auditory attention and selective input modulation: A topographical ERP study. NeuroReport 3:493-496

Paul DD, Sutton S (1972): Evoked potential correlates of response criterion in auditory signal detection. Science 177:362-364

Ricaurte GA, Guillery RW, Seiden LS, Schuster CR (1984a): Nerve terminal degeneration after a single injection of d-amphetamine in iprindole treated rats: Relation to selective long-lasting dopamine depletion. Brain Res 291:378-382

Ricaurte GA, Seiden LS, Schuster CR (1984b): Further evidence that amphetamines produce long-lasting dopamine neurochemical deficits by destroying dopamine nerve fibers. Brain Res 303:359-364

Shelley A-M, Ward PB, Michie PT, Andrews S, Mitchell PF, Catts SV, McConaghy N (1991): The effect of repeated testing on ERP components during auditory selective attention. Psychophysiology 28:496-510

Shelley A-M, Catts SV, Ward PB, Andrews S, Mitchell PF, Michie PT, McConaghy N, (1997): The effect of deceased catecholamine transmission on ERP indices of selective attention. Neuropsychopharmacology 16:202-210

Solomon P, Crider A, Winkelman JW, Turi A, Kamer RM, Kaplan LJ (1981): Disrupted latent inhibition in the rat with chronic amphetamine or haloperidol-induced supersensitivity: Relationship to schizophrenic attention disorder. Biol Psychiatry 16:519-537

Solomon P, Staton DM (1982): Differential effect of microinjections of d-amphetamine into the nucleus accumbens or the caudate putamen on the rat's ability to ignore an irrelevant stimulus. Biol Psychiatry 17:743-756

Solowij N, Michie PT, Fox AM (1991): Effects of long-term cannabis use on selective attention: An event-related potential study. Biol Psychiatry 40:683-688

Solowij N, Michie PT, Fox AM (1995): Differential impairments of selective attention due to frequency and duration of cannabis use. Biol Psychiatry 37:731-739

Stevens KE, Fuller LL, Rose GM (1991): Dopaminergic and noradrenergic modulation of amphetamine-induced changes in auditory gating. Brain Res 555:91-98

Topp L, Mattick RP, Lovibond PF (1995): The Nature of the Amphetamine Dependence Syndrome: Appetitive or Aversive Motivation? (Tech Rep No. 30). Sydney, Australia, National Drug and Alcohol Research Centre

Vasey MW, Thayer JF (1987): The continuing problem of false positives in repeated measures ANOVA in psychophysiology: A multivariate solution. Psychophysiology 24:479-486

Ward PB, Catts SV, Fox AM, Michie PT, McConaghy N (1991): Auditory selective attention and event-related potentials in schizophrenia. Br J Psychiatry 158:534-539

Weiner I, Lubow RE, Feldon J (1981): Chronic amphetamine and latent inhibition. Behav Brain Res 2:285-286

Weiner I, Lubow RE, Feldon J (1984): Abolition of the expression but not the acquisition of latent inhibition by chronic amphetamine in rats. Psychopharmacology 83:194-199

Weiner I, Lubow RE, Feldon J (1988): Disruption of latent inhibition by acute administration of low doses of amphetamine. Pharmacol Biochem Behav 30:871-878

Woldorff MG, Hillyard SA (1991): Modulation of early auditory processing selective listening to rapidly presented tones. Electoencephalogr Clin Neurophysiol 7:170-191 